\title{
Should Environmental Ethicists Fear Moral Anti-Realism?
}

\author{
ANNE SCHWENKENBECHER
}

Murdoch University

School of Arts

Murdoch WA 6150

Email:A.Schwenkenbecher@murdoch.edu.au

\section{MICHAEL RUBIN}

The University of Western Australia

School of Humanities

Crawley WA 6009

Email: Michael.Rubin@uwa.edu.au

\begin{abstract}
Environmental ethicists have been arguing for decades that swift action to protect our natural environment is morally paramount, and that our concern for the environment should go beyond its importance for human welfare. It might be thought that the widespread acceptance of moral anti-realism would undermine the aims of environmental ethicists. One reason is that recent empirical studies purport to show that moral realists are more likely to act on the basis of their ethical convictions than anti-realists. In addition, it is sometimes argued that only moral realists can countenance the claim that nature is intrinsically valuable. Against this, we argue that the acceptance of moral anti-realism is no threat to the environmentalist cause. We argue, further, that the acceptance of moral realism is potentially an obstacle to delivering on a third core demand: namely, that successful action on climate change and environmental destruction requires us to change some of our commonly held ethical views and, in so doing, to pursue and ultimately achieve a workable consensus.
\end{abstract}

\section{KEYWORDS}

Environmental ethics, moral realism, moral anti-realism, moral psychology, moral objectivism, intrinsic value 


\section{INTRODUCTION}

Environmental degradation and anthropogenic climate change pose some of the greatest challenges that humanity has ever faced. Many environmental ethicists have been arguing for decades that (i) swift action to protect our natural environment is morally paramount, and that (ii) our concern for the environment should go beyond its importance for human welfare: we should value the natural environment for its own sake. ${ }^{1}$ Do those who defend these commitments have good reason to favour a particular meta-ethic? Moral realism might appear best suited to provide the moral resoluteness and firm grounding of beliefs in nature's intrinsic value that environmental ethicists advocate. In contrast, moral anti-realism is often associated with the dangers of relativism and value anthropocentrism.

We take moral realism to be the conjunction of the following three theses:

1) Moral Cognitivism: moral thoughts are beliefs that have (non-deflationary) truth-apt propositions as their contents; moral sentences express these propositions.

2) Success Theory: there are moral facts; some of the propositions expressed by moral sentences are true. ${ }^{2}$

3) Stance Independence: the standards that fix the truth of moral propositions are not themselves justified, made correct or made true in virtue of the beliefs, attitudes, agreements or conventions of actual or hypothetical appraisers.

A meta-ethic that denies any one (or more) of these theses is a form of antirealism. Broadly speaking, there are three salient varieties of anti-realism: the error theory, moral constructivism and expressivism. Of these, moral error theory accepts (1) but denies (2): for the error theorist, moral thoughts are beliefs, but these beliefs are uniformly false. We concede that the error theory is probably an unwelcome meta-ethic for environmental ethicists; we therefore focus on the other two varieties. ${ }^{3}$ Moral constructivists accept (1) and (2), but deny (3): according to constructivists, moral facts are themselves ontologically dependent upon facts about what moral appraisers accept, or would accept under

1. There is great diversity in the views that fall under the umbrella of environmental ethics. However, we believe that these two propositions are fundamental for most - if not all - such views.

2. More specifically, success theory is the view that some positive moral propositions are true, where, roughly, a positive (deontic) moral proposition is one that entails the existence of a moral reason for someone to perform or refrain from performing an action.

3. Error theory is certainly unwelcome in its most barefaced, eliminativist form, which recommends that we abandon moral discourse altogether. Some error theorists, however, maintain that we can preserve moral discourse by treating morality as a fiction; see, for example, Richard Joyce (2001). 
certain conditions ${ }^{4}$ Finally, expressivists deny (1): on the most basic form of expressivism, an appraiser's thought is not a belief but a conative attitude of approval or disapproval. In uttering a moral sentence, a speaker expresses her attitude of (dis)approval towards some act or state of affairs. Do expressivists affirm (2) or (3) or reject them? This is a matter of dispute. Among the things we intend to argue in this paper is that, when (2) and (3) are properly understood, expressivists can accept both claims. This is argued in section 3, below. We will provide more detail on these theories as we develop our argument, but we should point out that we largely operate with generic versions of expressivist and constructivist forms of anti-realism.

Should environmental ethicists hope that realism gains widespread acceptance, or prefer for people generally to be anti-realists? At this point an important qualification is due. Empirical research seems to suggest that 'ordinary' people are not generally consistent in their meta-ethical beliefs (Goodwin and Darley 2008; Wright et al. 2013; Pölzler 2017). Rather, people appear to be realists about some moral beliefs and anti-realists about others. Our discussion of the acceptance of realism as (dis)advantageous to the environmental ethicists' cause is therefore fruitful only to the extent that people are (or are not) realists about those beliefs that directly concern the environmental cause. This includes beliefs about environmental values and virtues, aggregate harm and collective responsibility. In the following, then, we discuss the question of whether or not environmental ethicists should prefer people to be moral realists with regard to these particular beliefs.

Below, we consider and reject two arguments to the effect that ethicists who agree that (i) there is a need for swift action against environmental degradation, and that (ii) nature is valuable for its own sake, should want to see that moral realism gains widespread currency. Furthermore, we argue that the acceptance of moral realism is potentially an obstacle to delivering on a third core environmental ethicist demand: namely, that (iii) successful action on climate change and environmental destruction requires us to change some of our commonly held ethical views and to achieve politically feasible consensus. In section two, we discuss conceptual and empirical arguments purporting to show that people who accept moral realism are more strongly motivated to act on the basis of their moral judgements than those who do not. If these arguments are cogent, then it would seem that environmentalists have instrumental reason to favour the promulgation of realism over other meta-ethical

4. There is some dispute over whether constructivist views really belong on the anti-realist side in taxonomies of meta-ethics. The version of constructivism we have in mind is of the 'thoroughgoing' or 'meta-ethical' variety that invokes no prior substantive moral claims in setting up the construction procedure that 'fixes' moral facts. For more on the varieties of constructivism, see Sharon Street (2010).

5. This is assuming that environmental ethicists are fundamentally interested in solving environmental problems; see also Andrew Light's (2002b, 557ff) discussion on what environmental ethics is for. 
theories. ${ }^{6}$ We show that such conceptual arguments fail and, further, that the empirical evidence is inconclusive. In section three, we consider a second argument for the view that environmental ethicists should favour moral realism. Environmental ethicists have long defended the view that nature is intrinsically valuable. It is sometimes suggested that only realist theories of value can countenance the claim that nature has intrinsic value. ${ }^{7}$ We consider whether this is really so and conclude that, even though only moral realists can defend the objective value of nature, environmental ethicists can do without it.

After rebutting these two arguments in favour of moral realism, we present an argument against the desirability of a moral realist meta-ethic from an environmentalist point of view. We argue that, insofar as environmental ethicists demand that we adjust long-held moral views, acceptance of moral realism may well pose an obstacle to their agenda. We make a conceptual point to that effect, and also cite a recent empirical study suggesting that acceptance of realism inhibits individuals from changing their moral beliefs. In conclusion, we maintain that environmental ethics' core agenda might be better served if anti-realism were to gain widespread acceptance amongst people. Even if anti-realist meta-ethics fail to deliver so-called objective values, expressivists and constructivists can accommodate the values central to environmental and climate ethics - in particular, several sub-types of what has been labelled 'intrinsic' value. Anti-realists may be just as motivated to act on the basis of their moral beliefs, and are possibly more open to changing their mind and endorsing new notions of harm and responsibility. But crucially, acceptance of anti-realism holds a greater promise with respect to the achievement of a (new) moral consensus regarding our shared responsibility for collective harm to the environment.

\section{REALISM AND MORAL MOTIVATION}

Deliberation in environmental ethics is likely to yield the conclusion that currently existing individuals have a strong moral obligation to make significant sacrifices to their personal levels of well-being. This gives rise to a concern about moral motivation: even if individuals acknowledge that they have a moral obligation to scale back their environmental footprint, there is no assurance that they will comply with this obligation. It might be thought that realists are more likely than anti-realists to comply with their own moral convictions. In connection with the concerns of environmental ethicists, Darren Domsky (2004, 685-687) offers an argument along the following lines: because realists take their moral judgements to reflect objective, stance-independent moral

6. Darren Domsky (2003, 685-687) presses an argument along these lines in connection with the concerns of environmental ethicists.

7. Both Tom Regan (1981) and Holmes Rolston III (1994) advance arguments of this kind. 
facts, they acknowledge that the authority of morality has its source in something external to their own preferences. ${ }^{8}$ Insofar as they acknowledge this external authority, the argument goes, agents will be more likely to comply with what they acknowledge to be requirements of morality. Anti-realists, by contrast, do not take morality to have such an external authority. Indeed, the self-aware anti-realist understands that her moral commitments are shaped by contingent and arbitrary social and biological forces. Unfortunately, reflection on this kind of contingency makes it easier for us to dismiss or ignore the moral obligations that we affirm.

If the above line of reasoning were cogent, it would give environmental ethicists a pragmatic reason to prefer the widespread acceptance of realism to the acceptance of anti-realism. But are there good reasons to believe that antirealists are less likely to act on their moral convictions? Before we answer this question, let us clarify. There is, first, the (conceptual) worry that rejection of stance independence entails a belief in the less-than-categorical nature of our moral obligations. Second, there might be the (practical) worry that as a matter of fact those who believe in stance independence are more motivated to act on their moral convictions than those who do not hold that belief. We will address each worry in turn.

Let us begin by explaining how a sophisticated version of expressivism deals with the conceptual worry. Anti-realist expressivists take moral judgement to be essentially connected with certain conative attitudes. Where deontic moral judgements are concerned, the relevant conative attitude can be thought of as norm acceptance, or moral subscription to a norm. Very roughly, moral subscription to a norm, $n$, consists in an intention and a disposition both to conform one's actions to $n$, and to encourage others to conform to $n$. It also consists in a tendency to take a negative conative attitude (e.g. disapproval, anger or guilt) towards those who violate $n$ (see Copp 1995, ch.5; Gibbard 1990, ch.4). For an expressivist, moral judgements just are attitudes of norm acceptance or moral subscription. An appraiser judges that $x$ is wrong just in case she morally subscribes to a set of norms that forbid $x$. Her utterance of ' $x$ is wrong' expresses her attitude of subscription to a set of norms that forbids $x$ (see Gibbard 1990, ch.3).

Simon Blackburn mitigates the conceptual worry on behalf of expressivism as follows: an expressivist who acknowledges the contingent origins of her attitudes must ask herself whether the appropriate response to this knowledge is to take her obligations less seriously than she otherwise would. As Blackburn points out, however, this is itself a normative question. How the reflective expressivist answers the question depends upon whether the norms to which she subscribes prescribe taking her accepted obligations lightly, if they have contingent origins. Nevertheless, there is nothing that compels individuals to accept such a norm (Blackburn 1998, 286-291). In other words, the expressivist can

8. Our way of framing this argument also owes much to Simon Blackburn (1998, 286-294). 
insist that questions concerning stance independence are themselves asking about first-order moral matters; how an expressivist answers those questions will depend upon the kinds of norms to which she subscribes. Importantly, we should expect many expressivists to subscribe to norms that forbid certain kinds of action regardless of the social context in which those actions are performed. For instance, an expressivist can subscribe to a set of norms that forbid acts of striking children regardless of the social context, and even where the agents themselves belongs to a culture whose members subscribe to a contrary norm (see Blackburn 1984, 218; Gibbard 1990, 164ff).

Similar things might be said by certain types of constructivists. Consider, for instance, a form of procedural constructivism according to which an appraiser's judgement that a given act is wrong is just a belief with the propositional content that, were the appraiser's beliefs and values in reflective equilibrium, she would subscribe to norms that forbid that act. For a constructivist of this sort, the truth-conditions for a speaker's utterance of 'striking children is wrong' are determined by whether, were she in reflective equilibrium, she would subscribe to norms that prohibit striking children. If those norms make no exceptions for social context, then the constructivist speaks truly when she utters the sentence: 'striking a child is morally wrong wherever you happen to be from in the world'. It should be noted that we cannot focus on all or even the most important versions of constructivism here. ${ }^{9}$ We merely aim to show that the rejection of stance independence need not weaken or relativise our moral obligations.

It is worth noting that there is an influential argument suggesting that it is realists, rather than anti-realists, who face a problem with respect to ensuring that agents are motivated to fulfil what they judge to be their obligation. ${ }^{10}$ For expressivists, to judge that one has an obligation to perform an act is to have a certain motivational state that disposes the agent to perform the action (e.g. an attitude of approval towards performing the action). This means there is a necessary connection between judging an act to be obligatory for oneself and being pro tanto motivated to do it. By contrast, moral realists, especially those who subscribe to naturalism, take the connection between moral belief and moral motivation to be contingent. If this sort of realism is true, then convincing an agent that she is obligated to do $x$ does not suffice in ensuring that she has pro tanto motivation to do $x$. One would additionally need to ensure that she has a desire to do $x$ (or perhaps a de dicto desire to do that which is obligatory). It seems to us wise not to hang too much on the argument just canvassed here, however. Whether or not acceptance of realism yields greater or lesser

9. According to Street (2010), '[t]he most prominent characterizations of constructivism in ethics have important threads in common, but none would command universal assent, even among self-described constructivists' (364).

10. The argument sketched here has its origin in David Hume's ([1739] 2000) Treatise of Human Nature (see especially sect. 3.1.1) 
motivation to carry out what one judges to be obligatory for oneself is, ultimately, an empirical question, not one that can be settled by a priori analysis.

Even if the acceptance of moral anti-realism does not (conceptually) compel us to take our obligations lightly, the more important question is whether we in fact $d o$ take them more lightly, in the event that anti-realism is true and our moral attitudes have contingent origins. This is, as we have just suggested, an empirical question. A recent study by Liane Young and A.J. Durwin (2013) attempts to make some headway towards an answer. ${ }^{11}$ Young and Durwin's experimenters approached passersby and asked them to make a charitable donation. The subjects were divided into three groups. Subjects in the first group were asked a leading question, designed to prime them with realist beliefs: 'Do you agree that some things are just morally right or wrong, good or bad, wherever you happen to be from in the world?' A second group of subjects were asked a question intended to prime them with anti-realist beliefs: 'Do you agree that our morals and values are shaped by our culture and upbringing, so there are no absolute right answers to any moral questions?' A third group served as control, and were not primed with any meta-ethical question.

Young and Durwin report that, with one exception, every subject answered affirmatively to the meta-ethical question posed to them. ${ }^{12}$ After being primed, the subjects were asked to donate money to a charity for impoverished children. The researchers found that subjects primed with the anti-realist question were no less likely to donate money than the control group, which had not been primed. According to these findings, the contingency of our moral attitudes does not, in general, weaken our motivation to comply with the moral demands that we acknowledge. However, those subjects primed with the realist question were twice as likely to donate money than those in the control and anti-realist groups. If agreement with realism indeed strengthens people's moral resolve, ${ }^{13}$ then environmental ethicists would seem to have reason to hope that moral realism, rather than anti-realism, gains currency amongst ordinary people. While anti-realism may not make us worse off with respect to moral motivation, it does seem to impose an opportunity cost since it prevents us from reaping the motivational benefits that come with the acceptance of realism. ${ }^{14}$

11. To our knowledge, this is the first and only empirical study examining the link between meta-ethical realism and moral motivation. There exist a few studies discussing the relationship between moral deliberation in normative ethics and real-world behaviour, such as Schwitzgebel and Rust (2014), but this question does not concern us here.

12. Plausibly, they suggest that this can be explained by the fact that 'laypeople endorse certain aspects of both realism and anti-realism and, more generally, hold somewhat flexible, context-dependent meta-ethical views' (Young and Durwin 2013, 303).

13. Although Domsky's $(2004,685 \mathrm{f})$ claim that anti-realism imposes a motivational cost is confuted by Young and Durwin's study, his additional contention that realism confers a motivational benefit is hereby confirmed.

14. Anti-realists might object that it is not entirely obvious that Young and Durwin's findings with respect to charitable donations can be extended to the sorts of obligations moral agents hold with respect to nature. Indeed, most people see charitable donations as supererogatory 
There is significant ambiguity, however, in the formulation of the 'primes' in this study. The authors appear to equate moral anti-realism with moral relativism, and realism with universalism. In effect, the subjects in this study were primed with universalist versus relativist beliefs. Naturally, moral antirealism allows for moral relativism - the view that there are no universal moral standards ${ }^{15}$ - while realism does not. But anti-realism does not entail relativism; indeed, it is compatible with moral universalism. We can therefore say that the group that was primed with a relativist statement was primed with (a version of) anti-realism. The group that was primed with a non-relativist statement, however, was not clearly primed with regard to a particular metaethical stance. In other words, the 'realist' priming question used in Young and Durwin's 2013 study does not rule out various forms of moral anti-realism, including at least a generic type of proceduralist constructivism. Sophisticated anti-realists can (and, if they are decent, probably should) affirm the sort of questions that Young and Durwin utilise to prime their subjects with realistsounding thoughts. But if that is so, then the supposed motivational benefits of affirming such claims may be enjoyed by anti-realists, too. ${ }^{16}$

What the study seems to show, then, is that those who are definitely primed with a particular variety of anti-realism donate less than those who are primed with a view that is not clearly anti-realist. Yet it is also true that those who are primed with that particular version of anti-realism do not donate less than those who have not been primed at all, and who - for all we know - could be moral realists. ${ }^{17}$ In our view, Young and Durwin's study is therefore inconclusive as to whether a belief in moral realism yields motivational advantages that are unavailable to sophisticated anti-realists. However, nothing we have said rules out the possibility that a commitment to moral realism's unique features, such as moral objectivism, really does positively impact moral motivation. Perhaps future studies will show this to be so, but we are not aware of any existing study making the case for moral realism by linking objectivism (rather than universalism) with moral motivation. The upshot of this discussion seems to

actions. By contrast, environmental ethicists' aim is to encourage agents to accept that actions such as reducing one's carbon footprint are not merely supererogatory, but obligatory: the agent who wastefully emits greenhouse gasses, for example, does not merely fail to do good, but acts wrongly in causing aggregate harm. It might be argued that, where strict obligations are concerned, the motivational advantage of realist beliefs would remain unclear. We are nevertheless unsure whether this line of response is promising for anti-realism or not.

15. Or, to be more precise, according to moral relativism: '[m]oral claims are true only relative to some standard or framework; and [t]his standard or framework is not itself uniquely justified' (Levy 2002, 16).

16. Young and Durwin speculate about why realist-sounding claims might enhance agent's resoluteness. Nevertheless, the mechanisms they consider do not seem obviously at odds with the sort of explanations that an anti-realist might offer.

17. It is left completely open what the views of those in the control group might be. They may not have been primed with any type of belief, but it is at least possible in principle that they are all moral realists who are not willing to give much. 
be that environmental ethicists should perhaps fear moral relativism, or at least its widespread acceptance, rather than anti-realism. ${ }^{18}$

Finally, even if the acceptance of moral realism did itself enhance agents' compliance with their perceived moral obligations (and we have no evidence yet that it does), this would be a welcomed advantage only if those agents' moral judgements were shown to be true or otherwise desirable. Where an agent has profoundly misguided moral judgements, strengthening her resolve may well make matters worse. Consider, for instance, someone who is convinced that environmental regulations unjustifiably curtail important economic liberties and thus constitute a serious injustice. Strengthening this agent's resoluteness to comply with, to propagate and to enforce her perceived moral obligations would arguably make the world worse off, at least with respect to matters regarding the environment. In sum, strengthening the moral motivation of agents can benefit environmental ethics only when a sufficient number of agents accept the sorts of moral judgements that environmental ethicists seek to promote.

\section{ANTI-REALISM AND INTRINSIC VALUE}

One might still think that environmental ethicists should favour realism for its substantive advantages with respect to the content of first-order ethics. For instance, it is sometimes argued that, in order to satisfactorily ensure that humans will protect natural objects in the future, we must recognise in our ethical outlook a direct obligation to preserve and protect these entities; an ethic that recognises agents as having direct obligations only to other agents is insufficient to justify and motivate the kinds of actions necessary to mitigate environmental degradation and global climate change. Nevertheless, the argument continues, a direct obligation to protect nature can exist only if the value of natural entities obtains independently of human valuers. ${ }^{19}$

At this point, it should be noted that not all environmental philosophers are equally worried about the adequacy of indirect obligations to nature as the foundation of an environmental ethic. Environmental pragmatists such as Andrew Light point out that there may be practical advantages in embracing an anthropocentric notion of the value of nature (see also Weston 1985; O'Neill et

18. This conclusion seems to be supported by studies showing that simple exposure to moral relativism increases the likelihood of immoral behaviour in human agents (see, for example, Rai and Holyoak, 2013). In other words, the existing evidence hints at an inverse correlation between relativism and motivation.

19. For instance, Light writes that: '[s]ince the inception of environmental ethics in the early 1970s, the principal question that has occupied the time of most philosophers working in the field is how the value of nature could best be described such that nature is directly morally considerable, in and of itself, rather than only indirectly morally considerable, because it is appreciated or needed by humans' (Light 2002a, 426). 
al. 2008). According to Light's methodological environmental pragmatism, it is easier to motivate political action on environmental problems if we are able to appeal to 'human-centred motivations without endorsing crass versions of anthropocentrism', since humans tend to 'think about the value of nature in human terms' (Light 2002b, 561). In other words, Light thinks that not only should we be pluralists about the source of nature's value in philosophy, but that it can be advantageous for public policy to embrace some level of environmental anthropocentrism (see also Weston 1985). Our argument in the remainder of this section is thus directed at those who reject or are otherwise dissatisfied with environmental pragmatism.

The idea we are grappling with here is often expressed by the claim that an ethic that grounds direct obligations to preserve the environment must assign non-human natural entities (such as plants, ecosystems and non-human animals) some form of intrinsic value. ${ }^{20}$ Some environmental ethicists have argued that to ascribe intrinsic value to such entities is to ascribe to them a value that they possess independently of how they relate to moral appraisers. ${ }^{21} \mathrm{But}$ only moral realists, the argument goes, can accommodate the claim that some things possess value in this way. Because anti-realists (including pragmatists) reject stance independence, any value ascribed to an object must be grounded in facts about how that object relates to appraisers. ${ }^{22}$ Consequently, an antirealist meta-ethic cannot accommodate a first-order ethic that includes direct obligations to protect nature. Moral anti-realism, therefore, would deprive environmental ethicists of powerful argumentative resources.

Is it true that only realists can accommodate ascriptions of intrinsic value to non-human natural objects? It is sometimes argued that one's meta-ethical commitments place no constraints on one's first-order moral commitments. ${ }^{23}$ If that is right, then the realists' concern that anti-realism cannot accommodate intrinsic value judgements must be mistaken, and there is no cause for concern. We are doubtful, however, of the thesis that meta-ethical commitments do not constrain the availability of normative positions, ${ }^{24}$ and so we cannot help ourselves to such a quick dismissal of the realist's challenge.

20. Regan $(1981,31$ f) explicitly suggests that the intrinsic value of natural entities is sufficient to ground direct obligations to preserve those entities. It is less clear whether he takes their having intrinsic value as necessary for our having direct obligations to them. In any case, what is clear is that he takes such obligations in fact to be grounded in the intrinsic value of natural entities.

21. Authors who argue that natural objects possess value independently of moral appraisers include Rolston (1994), as well as Paul Taylor (1986) and Robin Attfield (1991). It should be noted, though, that Taylor uses the term 'inherent worth' for this kind of value.

22. The locus classicus for this kind of argument is G.E. Moore ([1922] 1959), yet both Regan (1981) and Rolston (1994) also advance arguments in this spirit.

23. John O'Neill (1992), for instance, writes that 'meta-ethical commitments are logically independent of ethical ones' (123).

24. At least one reason for such doubts is that certain forms of contractarian constructivism seem at least prima facie unable to accommodate the normative view that agents have direct 
Above, we distinguished three varieties of moral anti-realism: constructivism, expressivism and the error theory. We believe that some varieties of constructivism and expressivism can accommodate ascriptions of non-anthropocentric intrinsic value, as we shall argue below. Showing this is nevertheless complicated by some ambiguity as to what is meant by 'intrinsic value'. In what follows, we disambiguate these different meanings and argue that versions of anti-realist theories can accommodate all but one sub-type of "intrinsic value'.

It is increasingly common to use 'intrinsic value' to denote non-instrumental value - that is, value that does not depend upon its causing some further object or state of affairs that, itself, has value. ${ }^{25}$ Within this broad conception of intrinsic value as non-instrumental value, several narrower conceptions are possible. According to one salient understanding, a thing has intrinsic value if it has value that depends solely upon its intrinsic, non-relational properties. ${ }^{26}$ Let us call this Moore's conception of intrinsic value, since it is usually attributed to G.E. Moore. These two conceptions of intrinsic value are not equivalent. In fact, the broader conception countenances value based on extrinsic properties. To illustrate this point, consider an authentic Van Gogh painting alongside a perfect replica of it, painted by an anonymous art student. There is nothing incoherent about the claim that, whatever the non-instrumental value of the authentic Van Gogh, the replica is less valuable than the original. To account for this difference in value, however, one must identify a difference in the properties possessed by the two paintings. However, ex hypothesi, the paintings share all of the same intrinsic properties; the only salient difference between the two artworks concerns a relational, extrinsic property: one was painted by Van Gogh, while the other was not. Thus, at least some of the non-instrumental value of the original Van Gogh depends upon its extrinsic properties. The noninstrumental value of the Van Gogh is not equivalent to the value it has solely in virtue of its intrinsic properties.

A further way in which 'intrinsic value' has been understood is to mean objective value: value that is independent of any valuer, or that has its grounds

obligations to protect entities that are incapable of deliberation. For discussion of the relationship between meta-ethical commitments and normative commitments, see Sumner (1967), Tanner (2013) and Schroeder (2017).

25. Many environmental ethicists have criticised our traditional, commonsense ethical outlook for failing to ascribe non-instrumental value to nature. Not only do they consider this ethical outlook to be false, but also they fear that it prevents us from adequately addressing environmental problems. We find this sort of argument implicit in Sylvan (1973), for instance, and explicit in Katz (1987) or Katz and Oechsli (1993). The former, for instance, argues that the notion of intrinsic value is important but not all-important to environmental ethics; rather, 'it serves to limit the exclusive reliance on anthropocentric instrumental values' (Katz 1987, 240).

26. In 'The Conception of Intrinsic Value', Moore ([1922] 1959) writes that: '[t]o say that a kind of value is 'intrinsic' means merely that the question whether a thing possesses it, and in what degree it possesses it, depends solely on the intrinsic nature of the thing in question' (260). 
in something other than human beings and their attitudes. Let us call this the objective conception of intrinsic value. We have, then, at least three different conceptions of 'intrinsic value': non-instrumental value, Moorean intrinsic value and objective value. In the following, we consider each of these conceptions in turn, and discuss whether they can be accommodated by anti-realism and, further, whether they are essential for an environmental ethic.' .

Let us begin with non-instrumental value. As others have noted, anti-realists can accommodate moral judgements to the effect that states of affairs and objects - for instance, natural environments - have non-instrumental value (see, for example, O’Neill 1992; O’Neill et al. 2008). To see how expressivism can accommodate this moral judgement, let us begin with the observation that there is a certain conative state of mind that we can justly call valuing. It may be that this state of mind is reducible to other conative attitudes, such as desiring, or desiring to desire. But anti-realists can also allow that valuing is a sui generis mental state. Next, notice that one can value an object instrumentally or non-instrumentally. For instance, Adam can instrumentally value his collection of rare vinyls for how it helps him attract attention among his fellow students; alternatively, he can value the collection for its own sake. With this distinction in hand, we can build up to anti-realist accounts of evaluative judgements about what is good and bad.

For one kind of expressivist, an appraiser's judgement that a thing is noninstrumentally valuable can be identified simply with her non-instrumentally valuing that thing (see Blackburn 1998, 70). Alternatively, an expressivist can say that to judge that a thing is non-instrumentally good is simply to subscribe to norms that require non-instrumentally valuing that thing (see Gibbard 2003, 7). Since there is nothing conceptually or psychologically implausible about normal human appraisers non-instrumentally valuing natural environments (or subscribing to norms that require non-instrumentally valuing natural environments), expressivists have no trouble accommodating judgements to the effect that natural environments are non-instrumentally valuable.

In a similar way, non-instrumental value judgements can be accommodated by standard forms of moral constructivism. According to one kind of constructivist account of non-instrumental goodness, an appraiser's judgement to the effect that a thing is non-instrumentally good is a belief with the propositional content that she would non-instrumentally value that thing, if she were in an ideal epistemic position (see Lewis 1989, 113). On an alternative constructivist account, the relevant propositional content is that, if her beliefs and values were in reflective equilibrium, the appraiser would subscribe to a set of norms that requires non-instrumentally valuing the thing in question. Insofar as it seems conceptually possible that an agent in ideal epistemic conditions would instrumentally value nature, this kind of constructivism is compatible with the belief that nature has non-instrumental value. 
Opponents of anti-realism might find this unsatisfying. The anti-realist's way of understanding non-instrumental value judgements might be thought to make the value of nature too contingent an affair. According to this objection, anti-realists of the sort described above must still concede that, if we had a different psychology or different attitudes - that is, if humans failed to non-instrumentally value nature - then nature would have no non-instrumental value and we would have no direct obligation to preserve it. ${ }^{27}$ This, the objection continues, would be tantamount to denying that we have any direct obligation to preserve the environment at all: we only have such an obligation insofar as we care about (or value, or are disposed to value) the environment.

For expressivists, this sort of worry is easily parried. From their perspective, the claim that the environment would have no value if no one cared about it is just another first-order normative claim. To agree with such a claim is to subscribe to norms that contain the following prescription: value nature noninstrumentally, but do so only on the condition that people in fact value it thus. Surely, however, those of us who non-instrumentally value nature do not subscribe to norms that prescribe valuing it only on the condition that people in fact value nature. Instead, we subscribe to norms that prescribe non-instrumentally valuing nature, and that prescribe protecting it unconditionally. ${ }^{28}$ Constructivists can avail themselves of a similar manoeuvre to the one used by expressivists. Provided the norms that actual appraisers subscribe to in reflective equilibrium (or when assuming the practical point of view) prescribe an unconditional, non-instrumental valuing of nature, we speak falsely when we utter the sentence: 'if no one valued nature, nature would have no noninstrumental value, and there would be nothing wrong with destroying it'. ${ }^{29}$

Let us now turn to Moore's conception of intrinsic value. To start with, it is far from clear why non-instrumental value is not sufficient to ground direct obligations to protect the environment. It is hard to see what great advantages are lost if one has to concede that these obligations are ultimately grounded in relational properties of natural objects. The interest in enabling ascriptions of intrinsic value to nature was primarily to enable environmental ethicists to argue in favour of direct, non-contingent obligations to preserve the Earth's ecosystems. However, non-instrumental value ascriptions already suffice to ground such direct obligations. ${ }^{30}$ In fact, the demand that our duties to protect

27. Moore ([1922] 1959, 269) presses a more general argument along these lines.

28. Blackburn $(1984,217-220)$ responds similarly to the same kind of worry.

29. This kind of response on behalf of the constructivist is in the same spirit as Robert Elliot's (1996): namely, it rests on what might be described as a 'rigidification maneuver' (227). The truth conditions for our claims about what would be valuable in other possible worlds - including worlds in which we have very different psychologies - are fixed by facts about how we are disposed to value in the actual world (see also Lewis 1989, 132f).

30. When Moore ([1903] 1994) introduces the distinction between intrinsic and extrinsic value in Principia Ethica, he explains that the importance of the distinction is that only intrinsic value claims can ground universal moral principles. We note with interest that in Principia, 
the environment be grounded solely in the intrinsic properties of natural objects unnecessarily limits the range of considerations that can serve as moral reasons to preserve and protect. For instance, one might wish to point to an ecosystem's being untampered with by humans as moral grounds for protecting it - or at any rate, as grounds for preserving it, rather than, say, destroying it and replacing it with an engineered ecosystem.

There is nothing objectionably anthropocentric about a moral judgement of this sort. And yet, the property of being untampered with is surely an extrinsic property of any given ecosystem. Thus, if the sort of value required to ground direct moral obligations is value-dependent solely on intrinsic properties, we could not countenance the existence of an obligation to preserve or prefer untampered environments. In any case, as John O’Neill (1992) observes, anti-realists can accommodate intrinsic value judgements. For an expressivist, to judge an ecosystem intrinsically valuable in Moore's sense is just to noninstrumentally value the ecosystem because of its intrinsic properties. There is no reason to suppose that appraisers cannot so value an ecosystem. For the constructivist, meanwhile, an appraiser's judgement that an ecosystem is intrinsically valuable is a belief with the content that, were her beliefs and desires in reflective equilibrium, she would non-instrumentally value that ecosystem because of its intrinsic properties (ibid., 125).

So what about the third notion of intrinsic value: objective value, or value that is independent of appraisers? It might be argued that anti-realists cannot countenance judgements ascribing this kind of intrinsic value to objects. After all, whether or not a thing has value will depend, at least for constructivists, upon its relations to appraisers - in particular, on whether appraisers are disposed to value, or else to subscribe to norms that require valuing such a thing. The expressivist may meet this objection by explaining that the norm they express subscription to prescribes that agents value nature regardless of whether it is valued by actual appraisers. However, the constructivist might have to concede that this type of intrinsic value is unavailable to her. ${ }^{31}$ Exactly how great a disadvantage this is for the constructivist environmentalist is not clear but, as we shall see in section four, objectivism may well be an obstacle to their cause. ${ }^{32}$ Nevertheless, we do not think that this should make environmental

he contrasts intrinsic value with 'value as a means' (ibid., 72-75), or what we are calling instrumental value. For more argument to the effect that non-instrumental value is of greater moral importance than intrinsic value, narrowly defined, see Shelly Kagan's (1998) essay 'Rethinking Intrinsic Value'. Kagan's essay is noteworthy in that it advocates that the term 'intrinsic value' be expanded so that its denotation includes non-instrumental value that is grounded in an object's extrinsic properties.

31. Some scholars, such as Street (2016), have argued that anti-realist constructivists can also defend moral objectivity claims; however the level of that objectivity is not as robust as it is for realism, and the truth of moral claims ultimately depends on the judgements of the valuer.

32. In their empirical study on moral objectivism, Geoffrey Goodwin and John Darley (2010, 184) say that they 'would predict that if a moral value is thought to be objective, it is more likely to be afforded a sacred or protected status - and thus, an individual will be unwilling to 
ethicists wary of constructivism. On balance, for the environmentalists' aims, the most important conception of intrinsic value seems to be that of non-instrumental value, since it is sufficient to ground direct obligations to protect the environment. Further, as John O'Neill et al. (2008) point out: '[w]hile the rejection of realism does not rule out non-humans having intrinsic value, neither do realist positions rule it in' (118).

It may be worth addressing another kind of judgement that anti-realists might be thought unable to accommodate, and which environmental ethicists might be loath to give up. Even if anti-realists can accommodate judgements to the effect that nature has non-instrumental (and even intrinsic) value, they cannot accommodate the thought that nature has the property of being noninstrumentally valuable or important; nor can they accommodate the claim that it is a fact that nature is non-instrumentally valuable. This kind of objection is best seen as directed against expressivists, in particular. Constructivists, after all, have never denied that there are moral facts or properties; they claim only that such facts and properties are stance-dependent.

However, even expressivists accommodate judgements of this sort by adopting a deflationary or minimalist account of facts and properties. Paul Horwich $(1993,73-74)$ argues, for instance, that to say that it is a fact that $x$ is $F$, or that $x$ has the property of being $F$, is to say nothing more than $x$ is $F$ (see also Blackburn 1998, 75-83; Gibbard 2003, 182-183). Expressivists who adopt this strategy soon confront the question of what distinguishes this kind of expressivism from moral realism; after all, like realists, they are now willing to assent to the claim that there are stance-independent moral facts. The most straightforward reply cites the fact that expressivists offer an account of the function of moral discourse that is different from the account advanced by realists - namely, the central function of moral sentences is to express the acceptance of norms (see Stoljar 1993). In addition, Allan Gibbard highlights a difference in the order of explanation: whereas realists offer an account of moral judgements that begins with moral facts, expressivists offer an account of moral facts that begins with the nature of moral judgement - an account that does not, in the first instance, make reference to moral facts.

\section{REVISION, OBSTINACY AND CONSENSUS}

Finally, let us turn to an argument against moral realism's usefulness for the environmental ethicists' agenda. We argue that the widespread acceptance of realism may well be an obstacle to delivering on what many believe to be an indispensable shift in moral attitudes. The argument is roughly as follows: if (1) commonly held moral views, particularly on harm and responsibility, are

compromise on that value when deciding how to vote'. However, they concede that 'no data exist to support this contention, and so it is a task for future research to examine it' (ibid.). 
mistaken and detrimental to the environmentalist cause, and (2) in order to address environmental problems, (a large proportion of) moral agents need to change their views accordingly and (3) belief in the truth of moral realism makes people less likely to revise their moral views than beliefs in anti-realism, then (4) all other things being equal, a widespread acceptance of (or belief in the truth of) moral realism would be undesirable for the environmental ethicist.

As to the first two premises of the argument: environmental ethicists regularly argue that 'commonsense morality' is ill-equipped to support stringent obligations towards the environment, to acknowledge the moral wrongness of aggregate harms or to make us value nature in the way that we should. Consequently, many advocate for 'new' values and virtues (Jamieson 2010, 2014; O’Neill et al. 2008). For instance, Dale Jamieson (1992, 2010) thinks that commonsense morality's presuppositions about harm and responsibility stand in the way of perceiving individual actions as harmful in the context of climate change. He argues that, '[u]nless we develop new values and conceptions of responsibility, we will have enormous difficulty in motivating people to respond to this problem' (Jamieson 1992, 149f). Authors such as Judith Lichtenberg (2010) and Elizabeth Cripps (2011) argue that we have to move away from a widespread belief in harm as an individualist notion, and towards accepting that individually harmless actions that are harmful in aggregate may violate the harm principle. ${ }^{33}$

Turning to the third premise, we argue that a belief in moral realism may be an obstacle to revising one's moral views, based on the results of several empirical studies conducted by Geoffrey Goodwin and John Darley (2008; 2010 ; 2012) on moral objectivism. These studies found evidence that objectivist attitudes are correlated with a greater degree of closed-mindedness. ${ }^{34}$ They found that the more a subject treated a given moral judgement as objective, '[a] the less comfortable they were with another person's disagreeing with that belief, [b] the more immoral they thought this other person was, and [c] the less they thought it was possible they themselves could change their mind with respect to the belief in question' (Goodwin and Darley 2012, 254). To be clear, Goodwin and Darley have thus far uncovered only a correlation - they have not established whether objectivist attitudes cause obstinacy of this sort. However, they are fairly clear that ' $[\mathrm{p}]$ erceived objectivity negatively predicted participants' self-rated likelihood of ever giving up the moral belief over which disagreement had arisen' (ibid., 253), and they point out that: 'objectivity predicted both discomfort with a disagreeing other person ... and attributions of immorality to this person' (ibid.). A potential link between realist attitudes and

33. Derek Parfit (1986) has a similar point concerning collective harm more generally.

34. Goodwin and Darley focused on the 'objective' versus 'subjective' nature of moral beliefs, and therefore did not phrase the results of their research as claims about realism versus anti-realism. 
obstinacy should at least temper the degree to which environmental and climate ethicists welcome the spread of a realist moral outlook.

Two caveats are due at this point. First, one might wonder about the particular notion of objectivity used by Goodwin and Darley (2012), and whether it really corresponds to a realist outlook. One way in which they attempted to establish the perceived 'objectivity' of statements was to ask participants to agree or disagree with statements with ethically pertinent (and other) content, and to then indicate 'the extent to which they thought there was a correct answer as to whether each statement was true' on a six-point scale, 'with higher numbers indicating greater objectivity' (ibid., 251). A second measure of perceived objectivity was established by telling participants in a second stage that another person had disagreed with them concerning the initial statement, and to ask them about 'the extent to which they thought the disagreeing other person was mistaken, as opposed to neither party being mistaken' (ibid.). The authors write that: '[t]he two measures of objectivity were well correlated with each other ... and so for each item, we averaged these two measures to form a composite index of objectivity' (ibid., ellipsis added).

Goodwin and Darley's first measure of objectivity corresponds to what we have referred to as 'moral cognitivism' and 'success theory' - two of the key characteristics of moral realism - that is, the idea that moral propositions are truth-apt, and the idea that some moral propositions are actually true. While these are features of moral realism, they are also features of some forms of moral anti-realism, such as constructivism. In other words, the first measure of objectivity does not uniquely establish a realist position. What about the second measure of objectivity employed by Goodwin and Darley? Participants were asked if two contradicting moral propositions can both be correct. According to the authors, rejecting this claim is an indicator of an objectivist stance. But is it a measure of moral realism? Strictly speaking, rejecting this idea does not commit one to moral realism; constructivists and some types of expressivists may well reject this claim, too. In other words, Goodwin and Darley's second measure of objectivism does not directly match onto the third feature of realism as laid out above: stance independence. However, one might think that some of those who reject stance independence would happily agree that two contradicting moral propositions can both be correct: namely, relativists and subjectivists.

Goodwin and Darley's conclusions concerning the effects of what they call moral 'objectivism' may thus be thought not to transfer directly to moral 'realism', strictly speaking, since their measure of objectivism does not wholly correspond to a realist stance. However, we propose a more nuanced approach. Given that most 'ordinary' people are not scholarly meta-ethicists, it seems reasonable to think that those who would endorse Goodwin and Darley's objectivist claims are in fact those who (with regard to the issue in question) have realist tendencies. Most 'ordinary' people are not familiar with sophisticated 
versions of anti-realism and, when they disagree that two contradicting moral propositions on any given issue can both be correct, then it is very plausible to assume that they do so because they endorse stance independence and are thus realists, at least with regard to that particular issue. Moreover, if it so happens that people have a realist bent with regard to environmental virtues and values, then it appears that they would in fact be less inclined to change their mind in this regard, and would be less comfortable with those who disagree with them. ${ }^{35}$ This should make a realist stance look unattractive to environmentalists.

An additional argument against moral realism concerns the need to produce a politically feasible consensus on environmental values. Apart from greater reluctance to change one's mind, another source of concern arises from the correlation between realists' discomfort with diverging views and their greater attributions of immorality to those with whom they disagree. Light argued that having people on board is crucial to the success of the environmentalist agenda - and that, in order to get them on board, it would be wise to not discard anthropocentric values altogether. Indeed, in the face of rampant climatic change and environmental degradation there is a special urgency that the global community reach a workable consensus regarding our obligations vis-à-vis environmental protection.

\section{ANTI-REALISM AND CONSENSUS}

We believe that the strength of a moral anti-realist outlook lies in its better enabling such consensus. Before we argue for this, let us turn briefly to a counterargument. A realist might argue as follows: if we accept moral realism is true, then we accept that there is a single true standard of morally right action. Any moral disagreement would indicate that at least one party's beliefs are mistaken, and the recognition of this would spur parties to continue moral deliberation and inquiry until a consensus is reached. By contrast, if we accept some form of anti-realism, then we should not see fundamental moral disagreement as evidence that someone is mistaken in their moral judgements. Because each party has no grounds for thinking that their own moral judgements are defective, they have no reason - or at any rate, they have less reason than they would given the acceptance of realism - to remain engaged in debate or be willing to revise their own judgements in light of considerations brought forth by others. ${ }^{36}$

35. Goodwin and Darley (2012) observe that: '[o]bjectivity scores reliably predicted discomfort with another person' (252) and '[p]erceived objectivity negatively predicted participants' self-rated likelihood of ever giving up the moral belief over which disagreement had arisen' (253). One of the measures of discomfort seemed to be whether or not participants would have someone who they disagree with as a housemate.

36. David Brink $(1986,37)$ argues along these lines, while Robert Elliot $(1996,230)$ considers this sort of argument and offers a reply on behalf of moral constructivism. 
However, we argue that the prospects for consensus may well be more promising from an anti-realist outlook. Many anti-realists agree that the very point of moral discourse and deliberation is to facilitate social cooperation. On the constructivist side, John Rawls (1980) characterises an essential part of the 'social role of morality' as 'achieving the more or less minimum conditions of effective social cooperation, for example, by specifying standards to settle competing claims and setting up rules for coordinating and stabilizing social arrangements' (553). On the expressivist side, Allan Gibbard (1990, 76) writes: '[t]he chief biological function of normative discussion is to coordinate. Normative discussion allows for common enterprises and adjusts the terms of reciprocity...' (see also Blackburn 1998, 39; Lenman 2007, 75f). If this is the function of moral discourse, then, insofar as we engage in moral deliberation at all, there will be pressure on us to seek consensus with potential cooperators. Thus, Gibbard (1990) continues, '[f]or such a mechanism [as normative discussion] to work, two things are needed: tendencies towards consensus, and normative governance. Normative discussion must tend toward all accepting the same norms, and acceptance of norms must tend to guide action' (76). In defending his constructivist 'ideal advisor' account of normative reasons, Michael Smith ([1995] 2004) goes further: that the appraiser aims at consensus with other rational appraisers is constitutive of the sort of ideal normative deliberation that determines what the normative facts are (ibid., 27).

For the anti-realist, then, the very point of engaging in moral deliberation and inquiry would be undermined if she did not seek consensus with those in her community with whom she disagrees morally. For a realist, by contrast, the point of moral inquiry is to discover the stance-independent moral facts, whatever they may be. A failure of convergence should move us to revise our moral judgements, therefore, only if it indicates that our judgements do not accurately reflect the moral facts. But if we are not in doubt as to the accuracy of our own moral judgements, the mere fact of dissent gives us no reason to revise our judgements. Importantly, this point holds for both those realists who are little concerned with the environment and those who take to the other extreme and regard humans as planet Earth's 'disease'. If Light is correct, and a pragmatic and - above all - workable consensus is to be found at neither extreme, then constructivist and expressivist approaches to morality may be more promising than realism. ${ }^{37}$

37. Of course, an anti-realist may encounter interlocutors whose attitudes are so incongruent with her own that she concludes that engagement with those others will be pointless. Antirealism should therefore not be taken to counsel us to resolve all moral disagreements, no matter what our interlocutors' starting commitments may be. But, in this respect, the anti-realist's predicament is no different from the realist's. A realist who encounters an interlocutor whose moral judgements are vastly different from her own is likely to conclude that her interlocutor is so confused, blind or deluded that no amount of discussion will get that person on track. Moreover, the realist might see no prospect that her own mind will be changed by the thoughts of her interlocutor. 


\section{CONCLUSION}

To the extent that environmental ethics is concerned with promoting an environmentalist agenda, there may be good reasons not to overemphasise the objectivity of those values, to fight anti-realist attitudes or else to prefer ordinary people to be moral realists in this regard. Many plausible varieties of moral anti-realism enable us to ascribe non-instrumental value to nature. According to the empirical evidence available, avowals of moral anti-realism do not weaken agents' motivation to comply with their acknowledged obligations. Moreover, the sorts of realist avowals that seem to strengthen motivation are licensed by sophisticated anti-realist theories. Further, the acceptance of moral realism may come with significant disadvantages with respect to achieving a consensus on first-order ethical matters. Empirical research indicates that realist-sounding avowals are associated with a greater resistance to revising one's moral judgements, and a greater aversion towards dissenters. Since antirealists regard aiming at convergence to be constitutive of moral deliberation, anti-realist theories have at least one indisputable advantage with respect to the prospects of convergence.

Yet, to what extent is our argument specific to the domain of environmentalism? Clearly, questions of moral motivation, the source of moral value and the possibility of ethical consensus are of general importance to both lived morality and moral philosophy. However, we believe that these issues converge with a specific and growing urgency in the environmentalism debate that is unique to this domain. ${ }^{38}$ The question of objective (and therefore non-anthropocentric) value seems especially relevant to how we relate to nature, whereas it might seem less troubling where human wellbeing is directly concerned. Further, with the advent of dramatically accelerating climate change, there is an increasingly pressing, urgent need for a workable ethical consensus at the political level, and for morally motivated agents at the individual level. As we have shown in this article, environmentalists (which on our understanding includes all environmental ethicists) therefore have good reason to prefer at least some forms of moral anti-realism over realism.

\section{ACKNOWLEDGEMENTS}

The authors would like to thank the three anonymous reviewers for this journal for their invaluable feedback on previous versions of the paper. We would also like to acknowledge that this paper benefited greatly from comments by audiences at the Climate Ethics and Climate Economics Symposium at Graz University and the Department of Philosophy at Bayreuth University.

38. For a brief description of the 'special' status of environmental ethics, see Light (2002a), pp. 426-427. 


\section{MORAL ANTI-REALISM}

\section{REFERENCES}

Attfield, Robin. 1991. The Ethics of Environmental Concern. Athens, Georgia: The University of Georgia Press.

Blackburn, S. 1984. Spreading the Word. Oxford: Clarendon Press.

Blackburn, S. 1998. Ruling Passions. Oxford and New York: Oxford University Press.

Brink, D. 1986. 'Externalist moral realism'. The Southern Journal of Philosophy 24: 23-41. Crossref

Copp, D. 1995. Morality, Normativity, and Society. Oxford and New York: Oxford University Press.

Cripps, E. 2011. 'Climate change, collective harm and legitimate coercion'. Critical Review of International Social and Political Philosophy 14(2): 171-193. Crossref

Domsky, D. 2004. 'Keeping a place for metaethics: assessing Elliot's dismissal of the subjectivism/objectivism debate in environmental ethics'. Metaphilosophy 35(5): 675-694. Crossref

Elliot, R. 1996. 'Facts about natural values'. Environmental Values 5: 221-234. Crossref

Gibbard, A. 1990. Wise Choices, Apt Feelings. Cambridge, MA: Harvard University Press.

Gibbard, A. 2003. Thinking How to Live. Cambridge, MA: Harvard University Press.

Goodwin, G.P. and J.M. Darley. 2008. 'The psychology of meta-ethics: exploring objectivism'. Cognition 106: 1339-1366.

Goodwin, G.P. and J.M. Darley. 2010. 'The perceived objectivity of ethical beliefs: psychological findings and implications for public policy'. Review of Philosophy and Psychology 1(2): 161-188. Crossref

Goodwin, G.P. and J.M. Darley. 2012. 'Why are some moral beliefs treated more objectively than others?' Journal of Experimental Social Psychology 48: 250-256 Crossref

Horwich, P. 1993. 'Gibbard's theory of norms'. Philosophy and Public Affairs 22(1): 67-78.

Hume, D. (1739) 2000. A Treatise of Human Nature. Oxford and New York: Oxford University Press.

Jamieson, D. 1992. 'Ethics, public policy, and global warming'. Science, Technology, and Human Values 17(2): 139-153. Crossref

Jamieson, D. 2010. 'Climate change, responsibility, and justice'. Science and Engineering Ethics 16(3): 431-445. Crossref

Jamieson, D. 2014. Reason in a Dark Time: Why the Struggle Against Climate Change Failed - and What it Means For Our Future. Oxford: Oxford University Press. Crossref

Joyce, R. 2001. The Myth of Morality. Cambridge: Cambridge University Press. Crossref

Kagan, Shelly. 1998. 'Rethinking intrinsic value'. The Journal of Ethics 2(4): 277-297.

Katz, E. 1987. 'Searching for intrinsic value: pragmatism and despair in environmental ethics'. Environmental Ethics 9: 231-41. Crossref 
Katz, E. and L. Oechsli. 1993. 'Moving beyond anthropocentrism: environmental ethics, development, and the Amazon'. Environmental Ethics 15(1): 49-59. Crossref

Lenman, J. 2007. 'Expressivism and epistemology: what is moral inquiry?' Aristotelian Society Supplementary Volume 81(1): 63-81. Crossref

Levy, N. 2002. Moral Relativism. London: Oneworld Publications.

Lewis, D. 1989. 'Dispositional theories of value'. The Proceedings of the Aristotelian Society 63: 113-137.

Lichtenberg, J. 2010. 'Negative duties, positive duties, and the "new harms". Ethics 120: $557-578$. Crossref

Light, A. 2002a. 'Contemporary environmental ethics from metaethics to public philosophy'. Metaphilosophy 33(4): 426-449. Crossref

Light, A. 2002b. 'Taking environmental ethics public'. In D. Schmitz and E. Willott (eds), Environmental Ethics. What Really Matters. What Really Works, pp. 556566. Oxford and New York: Oxford University Press.

Moore, G.E. (1903) 1994. Principia Ethica. Cambridge: Cambridge University Press.

Moore, G.E. (1922) 1959. 'The conception of intrinsic value'. In Philosophical Studies, pp. 253-275. Patterson, NJ: Littlefield, Adams \& Co.

O’Neill, J. 1992. 'The varieties of intrinsic value'. The Monist 75(2): 119-137. Crossref

O’Neill, J., A. Holland and A. Light. 2008. Environmental Values. Abingdon: Routledge. Crossref

Parfit, D. 1986. 'Five mistakes in moral mathematics'. In Reasons and Persons, pp. 67-87. Oxford: Clarendon Press. Crossref

Pölzler, T. 2017. 'Revisiting folk moral realism'. Review of Philosophy and Psychology 8(2): 455-476. Crossref

Rai, T.S. and K.J. Holyoak. 2013. 'Exposure to moral relativism compromises moral behavior'. Journal of Experimental Social Psychology 49: 995-1001. Crossref

Rawls, J. 1980. 'Kantian constructivism in moral theory'. Journal of Philosophy 77(9): 515-572. Crossref

Rolston, H. 1994. Conserving Natural Value. New York: Columbia University Press.

Regan, T. 1981. 'The nature and possibility of an environmental ethic'. Environmental Ethics 3(1): 19-34. Crossref

Schroeder, M. 2017. 'Normative ethics and metaethics'. In T. McPherson and D. Plunkett (eds), The Routledge Handbook of Metaethics, pp. 674-686. New York: Routledge. Crossref

Schwitzgebel, E. and J. Rust. 2014. 'The moral behavior of ethics professors: relationships among self-reported behavior, expressed normative attitude, and directly observed behavior'. Philosophical Psychology 27: 293-327. Crossref

Smith, M. (1995) 2004. 'Internal Reasons'. Reprinted in Ethics and the A Priori; Selected Essays on Moral Psychology and Meta-Ethics. Cambridge and New York: Cambridge University Press. Crossref

Stoljar, D. 1993. 'Emotivism and truth-conditions'. Philosophical Studies 70: 81-101. Crossref

Street, S. 2010. 'What is constructivism in ethics and metaethics?' Philosophy Compass 5(5): 363-384. Crossref 


\section{MORAL ANTI-REALISM}

Street, S. 2016. 'Objectivity and truth: you'd better rethink it'. In R. Shafer-Landau (ed.), Oxford Studies in Metaethics: Volume 11, pp. 263-334. Oxford: Clarendon Press. Crossref

Sumner, L.W. 1967. 'Normative ethics and metaethics'. Ethics 77(2): 95-106. Crossref

Sylvan, R. 1973. 'Is there a need for a new, an environmental ethic?' Proceedings of the X11 World Congress of Philosophy 1: 205-210.

Tanner, J. 2013. 'Contractarianism and secondary direct moral standing for marginal humans and animals'. Res Publica 19: 141-156. Crossref

Taylor, Paul. 1986. Respect for Nature. Princeton: Princeton University Press.

Weston, A. 1985. 'Beyond intrinsic value: pragmatism in environmental ethics'. Environmental Ethics 7: 321-339. Crossref

Wright, J.C., P.T. Grandjean and C.B. McWhite. 2013. 'The meta-ethical grounding of our moral beliefs: evidence for meta-ethical pluralism'. Philosophical Psychology 26(3): 336-361. Crossref

Young, L. and A.J. Durwin. 2013. 'Moral realism as moral motivation: the impact of meta-ethics on everyday decision-making'. Journal of Experimental Social Psychology 49(2): 302-306. Crossref 